\title{
Perpetrators of different offences against females related to sexual activities, examined in Teaching Hospital Anuradhapura in 2014
}

\author{
Senanayake SMHMK
}

\begin{abstract}
Abstract

During the year 2014, 243 female victims of offences related to sexual activities had been examined medico-legally at Teaching Hospital Anuradhapura. A retrospective study was done based on the medico legal examination forms belong to females examined for complaints related to sexual activities at the medico legal unit of T.H. Anuradhapura during the year 2014. Details about age, complaint and type of perpetrator were collected and analyzed. According to the presenting complaint, eleven different offences related to sexual activities which had been perpetrated against the females were found. Among the perpetrators there were fathers, step fathers, grandfathers, other relatives, neighbors, and persons living in same village, boyfriends, friends, known persons and unknown persons. Perpetrators differ in different type of complaints. Known people were involved in $96.3 \%$ of sexual assaults. Father had been the perpetrator in 10/243 (4.1\%) of cases which exceeding sex assaults by strangers (9/243 or 3.7\%). Health education for prevention of sex assaults needs more attention on protecting females from known persons.
\end{abstract}

Key words: perpetrators, sex assaults, sexual intercourse, elope, inter-crural intercourse, fondling

\section{Full paper}

\section{Introduction-}

Anuradhapura district is considered as a district where the sexual assaults occur commonly. ${ }^{[1]}$ Therefore, analysis of the profile of different perpetrators in sexual offences would be important to understand their comparative involvement. Generally sexual violence against females includes penetrative assaults ${ }^{[2]}$ (such as forced vaginal, anal or oral penetration or drug facilitated sexual intercourse, incest) and non-penetrative assaults such as groping, forced kissing, sexual harassments (verbal or physical conduct of a sexual nature that affects an individual's work or school performance)andinter-crural intercourse. But in this article, complaints related to sexual activities are categorized according to the presenting complaint in medico-legal viewpoint.

All alleged sexual assault cases and any complaint related to sexual activity in Anuradhapura district are referred to the Teaching Hospital Anuradhapura, to

Senanayake SMHMK,

Consultant Judicial Medical Officer, Teaching Hospital Anuradhapura Corresponding author: Senanayake SMHMK, email: dilruksena62@yahoo.co.uk, Tel: +94718 195569

DOI: http://doi.org/10.4038/mljsl.v4i2.7337 be examined by experienced forensic medicine practitioners. During the year 2014, 243 such females had been examined for medico-legal purposes at Teaching Hospital Anuradhapura. During the medicolegal examination, details about perpetrator is routinely collected and investigations are performed to find evidence of contact. Aim of this study is to find the profiles of different perpetrators in different complains related to sexual activities and the prevalence of their involvement.

\section{Materials and method-}

A retrospective cross sectional study was conducted based on the medico legal examination forms (MLEFs) of all complains related to sexual activities against females examined at the medico legal unit of T.H. Anuradhapura during the year 2014. Age, presenting complaint and type of perpetrator were collected using a data collection form. Anonymous data were analyzed. 
Perpetrators were classified as fathers, step father, grandfather, brother in law, other relative, neighbor, and person living in same village, boyfriend, friends, known person (victim had communicated with him earlier but not a friend) and stranger (unknown person).

According to the presenting complaint of the victim and police, eleven different categories of offences related to sexual activities including sexual assaults were found against females. They are classified in to three groups as non-contact, contact and penetrative sexual activities. Non-contact offences were (1) verbal abuse with sex related words (2) exhibition of male genitalia (3) Nude photograph was taken. Contact offences were (4) Inter-crural intercourse (5) Fingering (6) Fondling/Touch (7) Abduction before the 18 years old where parents suspected sexual assault. Penetrative sexual offences were (8)Elope and sexual intercourse with the boyfriend before the age of 16 years ( statutory rape) (9) Consenting sexual intercourse was the presenting complain of two groups including female below the 16 years ( statutory rape) and female above the 16 years in which boyfriend had refused to marry the female. (10) Sexual intercourse by force or attempted for it (SIBFA) (11) anal intercourse.

Permission of the Director of the hospital was obtained to conduct the research.

Results- Findings are summarized in three tables and three charts.

Table 1. Prevalence of different types of perpetrators

\begin{tabular}{lll}
\hline Type of perpetrator & $\mathbf{n}(\mathbf{N}=\mathbf{2 4 3})$ & $\mathbf{( \% )}$ \\
\hline Boyfriend & 145 & $59 \%$ \\
Neighbor & 22 & 9 \\
Friend & 11 & 4.5 \\
Person living in the same village & 11 & 4.5 \\
Other relatives & 10 & 4.1 \\
Father & 10 & 4.1 \\
Stranger & 9 & 3.7 \\
Known person & 8 & 3.3 \\
Stepfather & 6 & 2.4 \\
Teacher & 5 & 2 \\
Grandfather & 3 & 1.2 \\
Brother in law & 2 & 0.8 \\
Husband & 1 & 0.4 \\
\hline \hline
\end{tabular}

Different categories of offences related to sexual activities against females are shown in Table 2. 
Table 2. Different categories of offences related to sexual activities against females

\begin{tabular}{lcc}
\hline \hline Offence related sexual activity & $\mathbf{n}(\mathbf{N}=\mathbf{2 4 3})$ & $\mathbf{( \% )}$ \\
\hline Elope and sexual intercourse before the age of 16 years & 108 & 44.4 \\
Consenting sexual intercourse (statutory rape or refusal of marriage) & 41 & 16.8 \\
Fondling /Touch & 31 & 12.7 \\
Sexual intercourse by force or attempt for it (SIBFA) & 30 & 12.3 \\
Inter-crural intercourse & 17 & 07.0 \\
Anal intercourse & 05 & 02.0 \\
Verbal abuse with words related to sex & 05 & 02.0 \\
Abduction before 18 years where parents suspected sexual assault & 03 & 01.2 \\
Fingering & 01 & 0.4 \\
Exhibition of male genitalia & 01 & 0.4 \\
Nude photographs taken & 01 & 0.4 \\
\hline \hline
\end{tabular}

Most commonly involved complaint and other involved complaints of each type of perpetrator are summarized in Table3. 
Table 3: Complaints of each type of perpetrator

\begin{tabular}{|c|c|c|}
\hline Type of perpetrator & $\begin{array}{l}\text { Commonest complaint } \\
\text { n (\%) }\end{array}$ & $\begin{array}{l}\text { Other involved complaints } \\
\text { n (\%) }\end{array}$ \\
\hline Boyfriend & Elope [108] (74\%) & $\begin{array}{l}\text { Consenting sexual intercourse [35](24\%), abduction [1] } \\
\text { naked photography after Inter-crural intercourse [1] }\end{array}$ \\
\hline Neighbor & (SIBFA) $[9](40 \%)$ & $\begin{array}{l}\text { Fondling [6] (27\%), Inter-crural intercourse [5] (22\%) } \\
\text { Anal intercourse [2] (9\%) }\end{array}$ \\
\hline Friend & Fondling [5] (45.4\%) & $\begin{array}{l}\text { Inter-crural intercourse [2] (18\%), consensual intercourse } \\
\text { [1] (9\%), SIBFA [1] (9\%), anal intercourse [1] }(9 \%) \\
\text { abduction [1] (9\%) }\end{array}$ \\
\hline $\begin{array}{l}\text { Person living in the } \\
\text { same village }\end{array}$ & $\begin{array}{l}\text { Inter-crural intercourse [5] } \\
(45.4 \%)\end{array}$ & Fondling [4] (36.4\%) SIBFA [2] (18.2\%) \\
\hline Other relatives & $\begin{array}{l}\text { SIBF }[4](40 \%) \\
\text { Fondling (4) (40\%) }\end{array}$ & $\begin{array}{l}\text { Consensual sexual intercourse } \quad[1] \quad(10 \%), \text { Anal } \\
\text { intercourse }[1](10 \%)\end{array}$ \\
\hline Father & SIBF [4] (40\%) & Inter-crural intercourse [3] (30\%) Fondling [3] (30\%) \\
\hline Stranger & SIBF [5] (55.5\%) & $\begin{array}{l}\text { Fondling [2] (22.2\%) Inter-crural intercourse [1] (11.1\%) } \\
\text { exhibition [1] (11.1\%) }\end{array}$ \\
\hline Known person & Fondling [7] (87.5\%) & SIBFA [1] (12.5\%) \\
\hline Stepfather & SIBF [4] (66.6\%) & $\begin{array}{l}\text { Consensual sexual intercourse [1] (16.6\%) Inter-crural } \\
\text { inter course [1] (16.6\%) }\end{array}$ \\
\hline Teacher & Verbal abuse [5] (100\%) & No other complains \\
\hline Grandfather & Equal involvement & $\begin{array}{l}\text { Inter-crural intercourse [1] (33.3\%) Fondling [1] (33.3\%) } \\
\text { abduction [1] (33.3\%) }\end{array}$ \\
\hline Brother in law & $\begin{array}{l}\text { Consensual sexual } \\
\text { intercourse [2] (100\%) }\end{array}$ & No other complains \\
\hline Husband & $\begin{array}{l}\text { Anal intercourse } \quad[1] \\
(100 \%)\end{array}$ & No other complaints \\
\hline
\end{tabular}

Different perpetrators involved in different categories of offences are shown in following three charts except elope category where all perpetrators were boyfriends. 
Non-contact offences such as different perpetrators of verbal abuse, exhibition and nude photography are shown in Fig. 1.

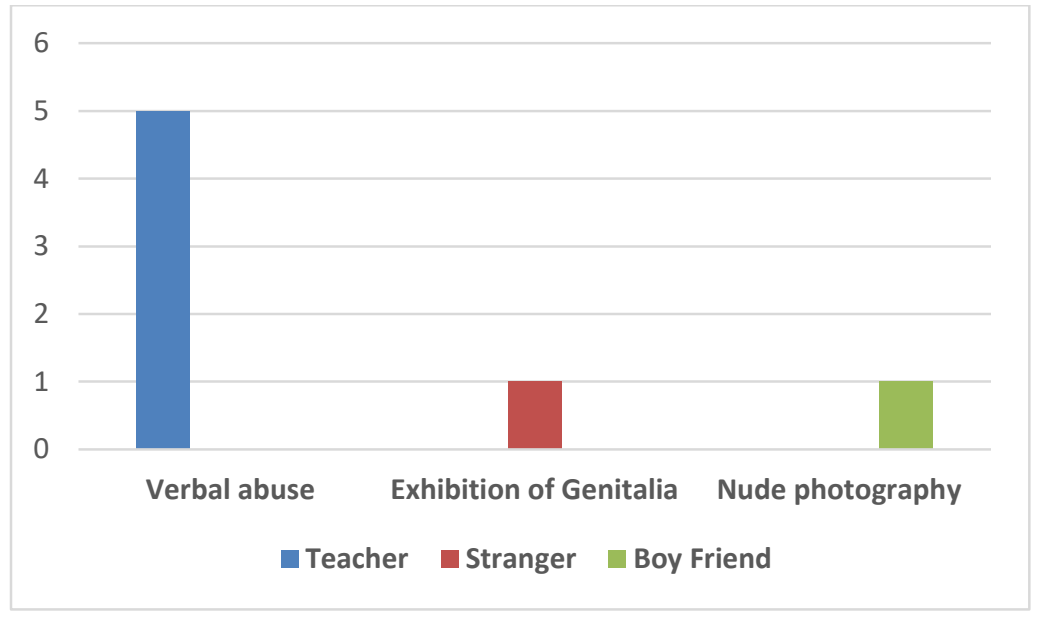

Figure 1. Non-contact offences

Contact offences such as different perpetrators of inter-crural intercourse, fingering, touch and abduction are shown in Fig. 2.

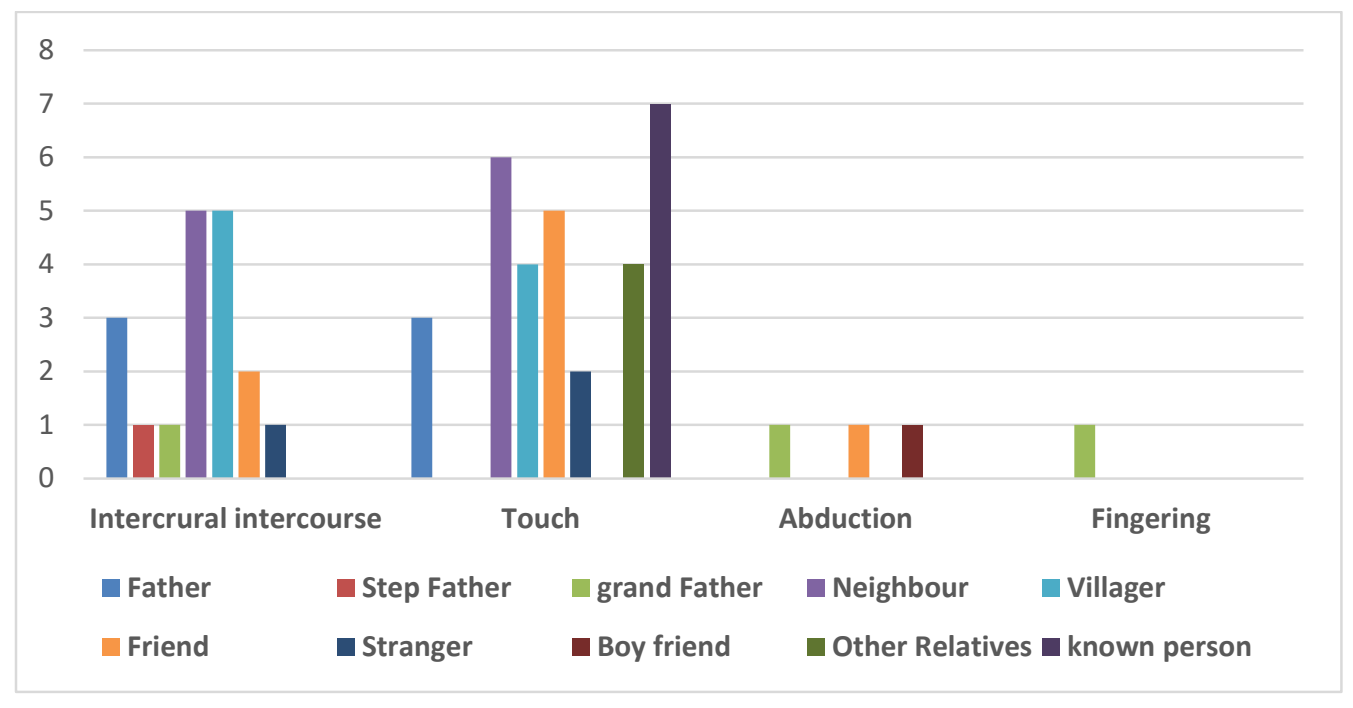

Figure 2. Contact offenses

Penetrative Offences except elope category such as perpetrators of consenting sexual intercourse, sexual intercourse by force and anal intercourse are shown in Fig. 3. 


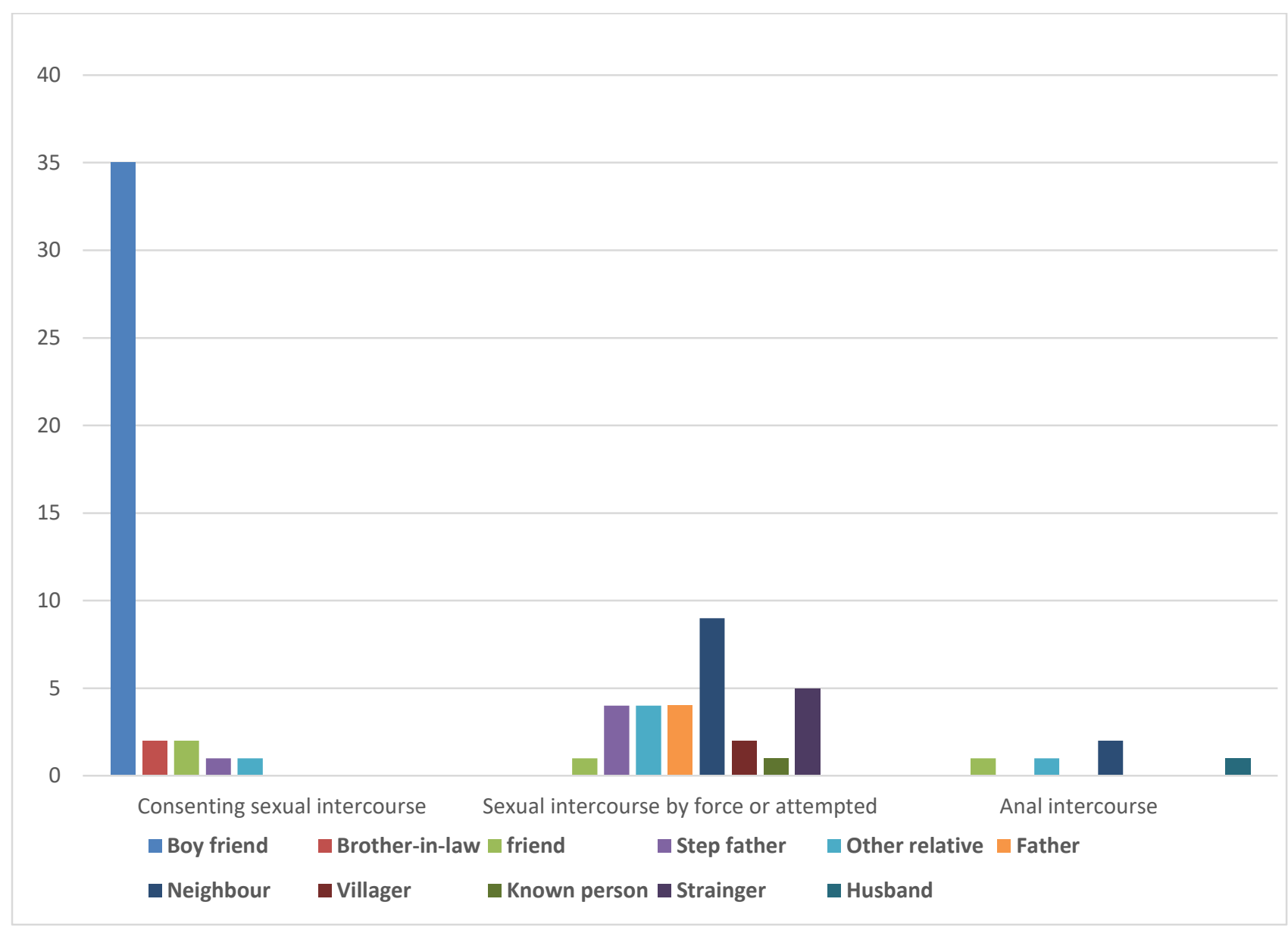

Figure 3. Penetrative offences

\section{Discussion}

Perpetrator is important in legal view point because ultimate target is to punish or rehabilitate the perpetrator. Medico-legally perpetrator is important because he/ she has different influences on examination findings. Physical and psychological Injury pattern may differ with the perpetrator ${ }^{[3]}$ because tactics used by perpetrators are different such as physical force, verbal coercion and victim impairment. ${ }^{[4]}$ Time of presentation may be different with different perpetrators because author had observed that sexual assaults by unknown people are presented soon with fresh injuries and sexual assaults by known people presents late. When the perpetrator is a beloved person, sometimes victim may try to protect him with false statements. ${ }^{[5]}$ All the perpetrators were males in this study. There was no involvement of multiple perpetrators such as gang rape.

Among perpetrators there were fathers, step fathers, grandfathers, brother in laws, other relatives, neighbors, and persons living in same village, boyfriends, friends, known persons (victim had communicated with him earlier but not a friend) and strangers (unknown persons). Boyfriends had involved with lot of complaints including elope and sexual intercourse before the age of 16 years and refusal of marriage after consensual sexual intercourse. Neighbors, friends and villagers are the next common types according to commonness. Thirty one relations were in this study group. It was $13 \%$ of perpetrators. Out of the 31 relatives, 10 fathers had involved and was the commonest relative to involve with offences related to sexual activities. 
Table 2 shows elope and consensual sexual intercourse are the majority (61\%) of offences. They all are preventable incidents with legal and health education and with proper care on female children.

Perpetrators are different in different categories of offences. They are summarized in three charts.

Sexual assaults in workplace is a newly emerging problem in the world ${ }^{[6]}$ and only one case is found in this study as attempted sexual intercourse by force by a coworker (known person). Anal intercourse is the only example of allegation against husband. Consensual sexual intercourse and refusal of marriage is the complaint made against intimate partner when the male refuses the marriage. After consensual sexual intercourse, when boyfriend refuses marriage female make complaint to police believing the boyfriend will marry her due to the legal inquiries. Even though it is not recognized as a crime, victim has an opportunity for future civil legal actions under the law of seduction.

Elderly sexual assault is victimization of persons over the age of 60. Globally the most common assailants are neighbors, caretakers, adult children, spouses and fellow facility residents. ${ }^{[7]}$ In Anuradhapura district out of 30 victims in SIBFA category, two elderly women victims were found assaulted by persons living in same village.

Strangers have involved in 3.7\% complains. 96.3\% perpetrators are relations or known persons. Therefore, health education on prevention of sexual assaults needs more attention about protection form known assailants. Protection strategies may be different with different types of assailants. Parents and victims should be more vigilant on known people who has more opportunity in communication and association with the female ${ }^{[8]}$ Considerable risk of sex assaults exists within the family such as from father, stepfather and grandfather. Incest is not uncommon in Anuradhapura district and consists of $8 \%$ cases. Oral intercourse was not complained by victims in the study group. Unfortunately, fathers have involved (10/243) in offences related to sexual activities more than strangers (9/243).

\section{Conclusion}

Boyfriend was the commonest perpetrator amount to $59 \%$ of all complaints. Thirteen percent of perpetrators were relatives. Father was the commonest relative involved. Father had involved in $4.1 \%$ of cases which exceeds sex related offences by strangers $4 \%$. Perpetrators differ in different type of sex assaults. Health education for prevention of sex assaults needs more attention on protection from known persons.

Acknowledgement- Dr. HA Karunathilaka, senior medicolegal practitioner, TH Anuradhapura for assistance provided.

\section{References}

1. Colombage SM, Dasanayake PB, Waidyarathna DL. A study on child abuse in Anuradhapura, Colombo South and Ratnapura. Colombo: Atlas Hall Ltd; 2005.pp-5,6

2. Catherine W. Child Abuse: sexual. In: McLay WDS. Editor. Clinical Forensic Medicine. New York: Cambridge university press; 2009.p-123

3. Abrahams N, Devries K, Watts C, et al. Worldwide prevalence of non-partner sexual violence: a systematic review. Lancet. 2014; 383: 1648-54.

4. Abbey A, Jacques AJ. Sexual Assault Perpetrators' Tactics: Associations with Their Personal Characteristics and Aspects of the Incident. Journal of Interpersonal Violence. 2011; 26: 2866-2889

5. Senanayake SMHMK. False history expressed by victims during medico-legal examinations: experience of a forensic medicine practitioner in Sri Lanka. Medicolegal journal of Sri Lanka.2015; $3(2): 25-27$

6. Harned MS, Omerod AJ, Palmeire PA, Collinsworth LL, Reed M. Sexual assault and other types of sexual harassment by workplace personnel: A comparison of antecedents and consequences. Journal of Occupational Health Psychology.2002; 7(2): 174-188. 
Medico-Legal Journal of Sri Lanka, 2016;4(2)

7. Malcolm G, Holt CSS. Elder Sexual Abuse in Britain: Preliminary Findings. Journal of Elder Abuse \& Neglect. 1993; 5(2): 63-71
8. Vadysingha AN, Senasingha DPP, Attygalle U, Ilangarathna Banda YMG, Ramanayake RS. A study on modes of communication in cases of sexual assault. Sri Lanka Journal of Forensic Medicine, Science \& Law. 2014;5(1):12-16 